\title{
CONSTITUCIÓN, TRIBUNAL CONSTITUCIONAL Y DERECHO PENAL NACIONAL
}

\author{
César San Martín Castro* \\ "El Derecho penal es, por naturaleza, un sistema normativo jurídica y legalmente limitado, \\ sujeto a garantías y garantizador de derechos y libertades" \\ Polaino Navarrete
}

\begin{abstract}
Resumen
En el marco del Estado de Derecho, el sistema jurídico-penal peruano siempre debe interpretarse a la luz de la Carta Constitucional vigente, pues allí emergen los contenidos axiológicos de las normas punitivas que regulan los procesos comunicativos de la sociedad peruana a fin de no generar estados de indefensión, así como tampoco ámbitos de impunidad. En el presente trabajo, el brillante autor nacional, expone de manera preclara los principios constitucionales del Derecho penal y la manera en que la Constitución permite una lectura garantista de las normas punitivas.
\end{abstract}

Palabras claves: Estado de Derecho, Carta Constitucional, principios constitucionales.

\section{Abstrac}

Within the framework of the State of Right, the Peruvian legal system always have to be interpreted according to the current Constitutional charter, because the fariness contents emerge there from the punitive norms that regulate the communicative processes of the Peruvian society in order not to generate defenselessness states, neither scopes of impunity. In the present work of a shining national author, is sets out the constitutional principles of the Criminal Law and the way in which the Constitution allows the prtected reading of the punitive norms.

Key words : State of Right, Constitutional charter, constitutional principles.

\section{Sumario}

1. Aspectos generales. 2. Principios constitucionales del Derecho penal. 3. Principio de legalidad. 4. Prohibición de analogía. 5. Irretroactividad de las normas penales desfavorables. $6 . \mathrm{Ne}$ bis in idem o doble punición. 7. Principio de proporcionalidad. 8. Principio de culpabilidad. 9. Principio de resocialización. 10. Principio de respeto y protección a la diversidad cultural. 11. ¿Interpretación constitucional de la legislación penal ordinaria?

\footnotetext{
* Vocal Titular de la Corte Suprema de Justicia de la República del Perú. Profesor de la Pontificia Universidad Católica del Perú.
} 


\section{ASPECTOS GENERALES}

El artículo $8^{\circ}$ de la Declaración Francesa de Derechos Humanos del 26 de agosto de 1789, estipuló que la ley no debe establecer más penas que las estricta y manifiestamente necesarias, y a su vez encarnó tanto la vigencia de los principios constitucionales de subsidiaridad y constitucionalidad del derecho penal, en tanto mandato dirigido al legislador, como los principios de legalidad y prohibición de analogía in malam partem, más concretamente dirigidos al juez; todos ellos enderezados a limitar el poder punitivo del Estado. El desarrollo del constitucionalismo y del penalismo modernos han venido a exigir no solo la incorporación en el ordenamiento jurídico de garantías penales básicas, sino también la superación de su mero contenido programático, para configurarlo en normas de aplicación directa y exigencia de un adecuado desarrollo legal con pleno respeto de su contenido esencial.

Es el tránsito a unas garantías de tipo material o de contenido, que además expresan una selección de valores fundamentales que se imponen a los poderes públicos como criterios materiales de legitimidad de su acción (Palazzo). Se trata, en suma, de la juridificación del fenómeno punitivo, su sometimiento al cumplimiento de una serie de fines trascendentes a lo punitivo y de contenido garantístico (Baratta).

El Tribunal Constitucional (TC) en la sentencia recaída en el Expediente $\mathrm{N}^{\mathrm{o}}$ 0047-2004-AI/TC, estableció que: “la Constitución es la norma de normas -lex superior- que disciplina los procesos de producción del resto de las normas y, por tanto, la producción misma del orden normativo estatal". Asimismo, en dicha sentencia señaló que: "La Constitución contiene un conjunto de normas supremas porque éstas irradian y esparcen los principios, valores y contenidos a todas las demás jurídicas restantes, por lo que el principio de jerarquía deviene en el canon estructura del ordenamiento estatal". Del mismo modo, indicó que: "La Constitución como norma jurídica vinculante y directamente aplicable constituye la premisa básica para que se erija como fuente de derecho y como fuente de fuentes. La Constitución, por lo tanto, no solo es una norma política -que contiene meras disposiciones orientadoras de la labor de los poderes públicos-, también es una norma jurídica, es decir, una norma con contenido dispositivo capaz de vincular a todo poder y a la sociedad en su conjunto (STC No 5854-2005-AA/TC). Esto es lo que se denomina primacía normativa de la ley constitucional".

Lo expuesto no hace sino ratificar que la Constitución orienta la política criminal del Estado y que la dogmática del sistema penal, desde la ley penal y 
en tanto proyección de los postulados constitucionales, se construye por la doctrina -teoría jurídica de los juristas- y la jurisprudencia -decisiones de los tribunales- también dentro de ese marco; una y otra tienen que adecuarse a las formas y valores de la Constitución y respetar tanto sus principios como sus valores superiores (Buitrago Ruiz).

Hoy en día, por consiguiente, resulta clarísimo y plenamente admitido que la Constitución -y, en esta perspectiva, el derecho constitucional- da directrices e impulsos al ordenamiento penal que lo van marcando progresivamente a "golpe" de sentencias del TC, aunque es de reconocer, por lo menos, tres ideas precisas: a) que el orden de valores jurídico-constitucionales y el orden legal jurídico-penal son espacios relativamente autónomos; b) que tienen sus presupuestos respectivos en diferentes objetivos y finalidades del actuar humano, que muestran regulaciones diferenciadas; y c) que la Constitución concede al legislador ordinario un amplio margen de libertad para la configuración del ordenamiento penal (Tiedemann). En este último punto, el TC en su sentencia recaída en el Expediente $\mathrm{N}^{\circ} 0014-2006-\mathrm{AI} / \mathrm{TC}$ sostuvo que se trata de un margen limitado por lo estrictamente necesario y en aras de la protección de bienes constitucionalmente relevantes, sin desnaturalizar los fines de la pena.

En la sentencia recaída en el Expediente $\mathrm{N}^{\circ}$ 0014-2006-AI/TC, el TC enfatizó que "[...] la política de persecución criminal del Estado, tiene un margen de razonabilidad para ello, pero con límites como los derechos fundamentales de las personas [...]". Ello no significa desconocer, desde luego, tanto la existencia de un sistema complejo de relaciones expresado en la presencia de un conjunto de preceptos que directa o indirectamente afectan y conforman el sistema punitivo (Arroyo Zapatero), como el efecto recíproco y la necesidad de una concordancia práctica entre la Constitución y el Derecho ordinario (Hesse).

El TC ha expuesto que las bases del derecho penal y de todas las ramas del derecho en general no hay que buscarlas en los códigos o en las leyes, sino en la Constitución, entendida como orden jurídico fundamental del actual Estado constitucional democrático. No obstante, en la sentencia recaída en el Expediente $\mathrm{N}^{\mathrm{o}} 14-2006-\mathrm{AI} / \mathrm{TC}$, el mismo TC ha llegado a decir, aunque con un cierto tufillo de superioridad errática, que ese órgano constitucional a través de la interpretación y la argumentación constitucionales contribuye a superar las limitaciones de la dogmática penal. Llama la atención, como nota marginal, que haya repudiado sin más, y sin entender a Jakobs, lo que la moderna ciencia penal está analizando bajo la denominación de derecho penal 
del enemigo -como si esa noción fuera una corriente político-criminal que postula una concepción y método de acción cerradamente inconstitucional, entrometiéndose en disputas teóricas sobre la materia-.

La dogmática del sistema penal es asunto de la doctrina y la jurisprudencia, es decir, forma parte del derecho ordinario y es monopolio de la jurisdicción ordinaria, lo que no margina por cierto que determinado ámbito de la dogmática esté abierto a la influencia directa del orden constitucional, que está dentro de las fronteras de la Constitución y en vinculación con la política criminal (Tiedemann). Esto último es lo que viene a explicar los intentos muy serios de formular un concepto constitucional de delito $y$, desde esa perspectiva, la Constitución desempeña un papel determinante respecto a la dogmática penal en la medida en que regula los derechos fundamentales, incorpora normas que directa o indirectamente rigen la materia penal e, incluso, contiene directrices de política penal que orientan o delimitan la tarea del legislador ordinario (Cobo/ Vives).

\section{PRINCIPIOS CONSTITUCIONALES DEL DERECHO PENAL}

Los principios que introduce la Constitución, vista su calidad y cantidad -lógicas intensivas y extensivas del ordenamiento constitucional-, no pueden menos que calificarse como un programa penal de la Constitución, que implican un conjunto de postulados político-criminales genéricos, que protegen al ciudadano de un derecho penal anticonstitucional aunque no contra una mala política criminal, dada la libertad reconocida al legislador ordinario para resolver a su prudente arbitrio los problemas concretos que se le plantean; mala política criminal que, hoy en día, se expresa -entre otros factores- en la hipertrofia del sistema penal en su conjunto (Palazzo).

Existe un conjunto de principios, de alcance general, referidos a todo el ordenamiento que inciden, directa o indirectamente, en el derecho penal. Entendemos por principios aquellos postulados, de alcance general con proyección en el sistema penal, que informan todo el ordenamiento jurídico, previstos explícita o implícitamente en la Constitución y, por ello, tienen un carácter supremo que expresa la filosofía incorporada en la Ley Fundamental. Lo particularmente remarcable cuando se está ante principios de relevancia constitucional es que cuando entran en conflicto genera un problema hermenéutico que no se resuelve solamente con las reglas tradicionales o comunes de interpretación, sino con las técnicas del balance o de la ponderación y de la armonización. La primera implica tener en cuenta el caso concreto, el mayor peso o valor, axiológicamente hablando, de un principio sobre otro y el sacrificio de 
un principio respecto del otro, todo siempre sobre la base de decidir con fundamento lo más justo o lo menos injusto; y la segunda, conduce a la búsqueda de una solución teniendo en cuenta que la Constitución es una unidad, que sus disposiciones no se pueden mirar aisladamente y que sus normas, en caso de tensión entre ellas, deben ser concordadas (Pérez Pinzón).

Los denominados valores superiores de libertad, justicia, igualdad y proporcionalidad, entendidos como componentes estructurales básicos del orden constitucional, han de informar el conjunto de la organización jurídica y política, y orientar e impulsar todos los ámbitos del Derecho (sentencia del Tribunal Constitucional recaída en el Expediente $\left.N^{\circ} 0976-2001-A A / T C\right)$. Los dos últimos tienen una suerte de traducción o anclaje específico en el Derecho penal, radicados en la proporcionalidad de las penas y en la protección de la diversidad cultural y consecuente reconocimiento de un ordenamiento de relativa autonomía para los indígenas. En el ámbito de la libertad personal, el TC en su sentencia recaída en el Expediente No 2496-2005-HC/TC expresó no solo que es un derecho fundamental reconocido, sino también un valor superior del ordenamiento jurídico, pero su ejercicio no es absoluto e ilimitado, pues se encuentra regulado y puede ser restringido mediante ley.

A continuación veremos algunos mandatos, prohibiciones y regulaciones. Así, por ejemplo:

2.1. La prohibición de la tortura $\mathrm{u}$ otros tratos inhumanos o degradantes (artículo $2^{\circ} .24$.h de la Constitución), cuya base es la protección del derecho fundamental a la integridad personal (sentencia del Tribunal Constitucional recaída en el Expediente $\mathrm{N}^{\mathrm{o}}$ 2333-2004-HC/TC).

2.2. La prohibición de la prisión por deudas, artículo $2^{\circ}$.24.c de la Constitución, que garantiza -como acota la sentencia del Tribunal Constitucional recaída en el Expediente $\mathrm{N}^{\mathrm{o}}$ 2892-2003-HC/TC-que las personas no sufran restricción de su libertad locomotora por el incumplimiento de obligaciones, cuyo origen se encuentra en relaciones de orden civil. Son relevantes, sobre el particular, la sentencia del Tribunal Constitucional recaída en el Expediente $\mathrm{N}^{\circ}$ 1428-2002$\mathrm{HC} / \mathrm{TC}$, que determinó que la revocación de la condicionalidad de la pena por omisión voluntaria del pago de la reparación civil no constituye una lesión del derecho a la libertad individual, pues como luego enfatizó la sentencia del Tribunal Constitucional recaída en el Expediente $\mathrm{N}^{\circ}$ 7361-2005-HC/TC, "[...] el origen de la obligación de pago se afinca en el ámbito penal, sede en que se condenó a la beneficiaria imponiéndosele como condena el reparar el daño ocasionado por el delito" y antes mencionó la sentencia del Tribunal Constitucional recaída en el Expediente $\mathrm{N}^{\mathrm{o}}$ 893-2004-HC/TC que la obligación 
de pagar la reparación civil es una verdadera condición de la ejecución de la sanción penal. Asimismo, la sentencia del Tribunal Constitucional recaída en el Expediente $\mathrm{N}^{\circ}$ 7361-2005-HC/TC declaró que ese incumplimiento, doloso o culposo, también autoriza a impedir la concesión de un beneficio penitenciario de excarcelación en tanto la ley así lo disponga.

Desde la tipicidad del delito de omisión de asistencia familiar (artículo $149^{\circ}$ del Código Penal), cabe sostener que no es posible considerar que se trate de la excepción al mandato judicial por incumplimiento de deberes alimentarios, pues lo que ese tipo legal castiga es el incumplimiento de resoluciones judiciales y no meros convenios entre particulares (Reyna Alfaro); centrado en "[...] deberes de tipo asistencial, donde prevalece aún más la idea de seguridad de las personas afectadas [...]" (Salinas Siccha. Cfr. ejecutoria superior del 21 de mayo de 1998-Lima); por lo que el bien jurídico que se protege no es el crédito en cuanto tal, ni persigue sancionar el incumplimiento de una obligación civil, sino proteger a los miembros económicamente más débiles de la unidad familiar (v.gr. sentencias del Tribunal Supremo español del 28 de julio de 1999, 13 febrero de 2001 y 3 de abril de 2001. En contra, Serrano Gómez).

2.3. La exigencia de criminalización del tráfico ilícito de drogas y del enriquecimiento ilícito (artículos $8^{\circ}$ y $41^{\circ}$ de la Constitución), que pueden clasificarse como una cláusula de penalización. Sobre el tráfico ilícito de drogas la sentencia del Tribunal Constitucional recaída en el Expediente $\mathrm{N}^{\circ}$ 0016-2001-HC/TC ha expuesto que constituye "[...] un hecho despreciable en la conciencia social de la población y ocasiona un daño calificado a la sociedad", por lo que es de deducir que para el TC las conductas vinculadas al comercio ilícito de drogas constituyen un bien merecedor de tutela penal. Con relación al delito de enriquecimiento ilícito, lo considera un ámbito incardinado en el concepto de criminalidad gubernativa y expresión de una política criminal en la lucha contra la corrupción, advertida por la Constitución como particularmente disvaliosa, al punto que ha estructurado no solo medidas preventivas, sino que ha hecho alusión a una de las concretas manifestaciones de los delitos de corrupción y a reglas específicas a aplicarse para su procesamiento, referidas a la intervención del Fiscal de la Nación y a la duplicación del plazo de prescripción en caso de delitos cometidos contra el patrimonio del Estado (sentencia del Tribunal Constitucional recaída en los Expedientes $\mathrm{N}^{\mathrm{o}} \mathrm{s}$ 1076-2003-HC/TC y 8-2005-PI/TC).

2.4. Determinados preceptos que consagran los derechos fundamentales. Entre los que destacan los de derechos de libertad de expresión, de asociación y de reunión. 
2.5. El derecho a la libertad de expresión (artículo $2^{\circ} .4$ de la Constitución) ha sido entendido, al mismo tiempo, como derecho subjetivo y garantía institucional del sistema democrático constitucional, a la vez como libertad preferida, en particular cuando su ejercicio permite el debate sobre la cosa pública (sentencia del Tribunal Constitucional recaída en el Expediente $\mathrm{N}^{\circ}$ 905-2001-AA/TC).

Por ello, la sentencia del Tribunal Constitucional recaída en el Expediente $\mathrm{N}^{\circ}$ 0003-2005-AI/TC, v. gr. estimó que el delito de apología terrorista no vulnera esa libertad, pues ese derecho persigue, garantiza y protege otros derechos constitucionales, además que la Constitución y el Derecho internacional de los derechos humanos no prohíbe que el legislador penal pueda criminalizar determinados contenidos de un discurso -el ejercicio de este derecho, como se enfatizó en la sentencia del Tribunal Constitucional recaída en el Expediente $\mathrm{N}^{\mathrm{o}} 6712-2005-\mathrm{HC} / \mathrm{TC}$ no es libre ni irrestricto, está sujeto a ciertos condicionamientos que deben ser respetados dentro de un Estado de Derecho, límites que deben encontrarse en la propia Constitución-.

2.6. El derecho de asociación (artículo $2^{\circ} .13$ de la Constitución), cuya fundación y funcionamiento si bien no requiere autorización previa debe hacerlo "[...] con arreglo a la ley" (sentencia del Tribunal Constitucional recaída en el Expediente $\mathrm{N}^{\mathrm{o}} 4-1996-\mathrm{AI} / \mathrm{TC}$ ). El marco jurídico que instituya la ley, desde luego, puede criminalizar a los miembros de aquellas asociaciones, entendidas como una unión de personas caracterizada por las notas de organización y permanencia (Vives/ Carbonell), que persigan fines o utilicen medios tipificados como delito -se trata de dos supuestos materialmente equivalentes-, referido el primero a una asociación que nace ya ilícita y el segundo a una que, luego, pasa a ser ilegítima (Tamarit Sumalla). La conducta que se sanciona, conforme a lo dispuesto por el artículo $317^{\circ}$ del Código Penal, tiene declarado la Corte Suprema en el Acuerdo Plenario $N^{\circ}$ 4-2006/CJ-116, es el solo hecho de formar parte de la agrupación a través de sus notas esenciales, que le otorgan una sustantividad propia de: a) relativa organización, b) permanencia o estabilidad, y c) número mínimo de personas -sin que se materialicen sus planes delictivos-; se consuma desde que se busca una finalidad ya inicialmente delictiva, no se requiere que se haya iniciado la fase ejecutiva del delito buscado. Es muy importante para la determinación de los delitos de asociación ilícita, y ahora de la criminalidad organizada, la previa definición de los alcances del derecho de asociación. El bien jurídico protegido en el delito de asociación ilícita, como se sabe, lo constituye el ejercicio del derecho de asociación, comportando los supuestos tipificados (artículo $317^{\circ}$ del Código Penal) claras extralimitaciones al ejercicio constitucional de tal derecho y, por ende, legítimamente sancionados. 
2.7. El derecho de reunión (artículo $2^{\circ} .12$ de la Constitución), definido en la sentencia del Tribunal Constitucional recaída en el Expediente $\mathrm{N}^{\circ}$ 4677-2004$\mathrm{AA} / \mathrm{TC}$ como la facultad de toda persona de congregarse junto a otras, en un lugar determinado, temporal y físicamente, y sin necesidad de autorización previa, tiene como elemento finalista esencial que su ejercicio sea lícito, predicable no solo del propósito último de la reunión, sino de los medios en que pretende ser alcanzado. En consecuencia, la represión se legitima cuando se advierte una intencionalidad lesiva y la concreta actividad violenta durante la congregación de los individuos involucrados en ella. Precisamente, el Código Penal (artículo $315^{\circ}$ ) reprime el delito de disturbios, cuya relación con la libertad constitucionalmente protegida estriba en que, como por ejemplo señala el Tribunal Supremo español en la Sentencia No $N^{0}$ 1016-1993 del 6 de febrero de 1991, deberevestir cierta gravedad y entidad, nocastigándoseen caso contrario estas conductas sobre la base de los principios de proporcionalidad y de intervención mínima del derecho penal. Esa misma capacidad de poner en peligro la tranquilidad pública y crear un estado de inseguridad, ha sido destacado por la Corte Suprema en la Ejecutoria No 1971-97/Puno del 13 de enero de 1998. Por lo demás, como precisó el Tribunal Supremo español en la Sentencia No 2083-1994 del 29 de noviembre de 1994, no es obstáculo para la existencia del indicado delito el hecho de que la finalidad de la reunión sea plenamente legítima, como lo puede ser la protesta o la reivindicación que la actuación en grupo desea poner de manifiesto.

Cabe acotar, como dice Alexy, que la interpretación constitucional de los derechos fundamentales se concibe como un ejercicio de racionalidad tendiente a evitar decisiones arbitrarias.

2.8. Algunos preceptos que regulan conceptos del sistema penal. Es de mencionar, por ejemplo, la inviolabilidad parlamentaria, la jurisdicción indígena y la amnistía (artículos 93 , II párrafo; $149^{\circ}$ y $102^{\circ} .6$ de la Constitución).

2.9. La inviolabilidad, respecto de la que aún no se ha pronunciado el TC, desde la perspectiva constitucional, debe entenderse como una garantía constitucional indeclinable de determinados órganos del Estado frente a otros (judiciales), con el objeto de que puedan cumplir su función de manera imparcial (Cuello Contreras). En concreto, la razón de esta institución radica en la protección del discurso parlamentario y en la libertad de voto (Jescheck). Dogmáticamente es concebida como una causa de justificación -aunque otro sector de la doctrina la califica de causa personal de exclusión de pena-, en cuya virtud los congresistas, el Defensor del Pueblo y los magistrados del 
Tribunal Constitucional "[...] no pueden ser sancionados por ningún delito de expresión que cometan al exponer opiniones durante el ejercicio de su cargo" (Hurtado Pozo).

2.10. La amnistía ha sido definida por el TC en la sentencia recaída en el Expediente $\mathrm{N}^{\circ}$ 0013-1996-AI/TC en los siguientes términos: “[...] es un derecho que el Congreso ejerce en nombre de la sociedad, a fin de aplicar el olvido a ciertos tipos de delito, los cuales se tienen como hechos no punibles, y se consideran como nunca perpetrados". La amnistía se ejerce a través de leyes -que pueden ser dictadas antes, durante o después del proceso y de la condena-, caracterizadas por ser leyes desincriminatorias anómalas porque el delito es borrado de modo anómalo al dar lugar a una desincriminación temporaria, extraordinaria o excepcional, cuyo límite o impedimento se encuentra en aquellos delitos que no lo permiten en razón de tratados internacionales o los cometidos por los propios legisladores -que en este último caso importarían la legitimación del encubrimiento- (Zaffaroni).

2.11. Es posible identificar, desde las exigencias del ordenamiento penal, cinco principios connaturales de directa relevancia constitucional que abordaremos sucintamente. Son los principios de legalidad penal, proporcionalidad, culpabilidad, resocialización y protección de la diversidad cultural, muchos de los cuales incluso se han convertido en Derechos fundamentales.

\section{PRINCIPIO DE LEGALIDAD}

Está previsto en el artículo $2^{\circ} .14$.d de la Constitución Política, y el TC, en la sentencia recaída en el Expediente $\mathrm{N}^{\mathrm{o}}$ 1805-2005-HC/TC lo considera como un derecho subjetivo constitucional de todos los ciudadanos. Es el principal límite impuesto por las exigencias del Estado de Derecho al ejercicio de la potestad punitiva (Muñoz Conde/ García Arán), que se erige como garantía de legitimación y garantía de seguridad (García Rivas) y tiene como fundamentos: a) el político constitucional, ligado a la división de poderes y a la democracia; b) el axiológico, orientado a la seguridad jurídica; y c) el jurídico-penal, centrado en su efecto preventivo general y permite el desarrollo y afianzamiento de la conciencia jurídica de la población (U rquizo Olaechea).

La sujeción que el principio de legalidad debe garantizar es la objetividad, en cuya virtud, apunta Jakobs, el comportamiento punible y la medida de la pena se deben determinar por anticipado y con validez general, precisamente mediante una ley determinada dictada con anterioridad al hecho; principio que abarca a todos los presupuestos de punibilidad y no está limitado al 
ámbito de lo imputable (especialmente, también, la prescripción, que ha de estar legalmente determinada y no cabe prorrogarla retroactivamente, tanto si antes del acto de prórroga ha expirado el plazo).

Este principio incorpora varios subprincipios que expresan, por un lado, el tenor literal y por el otro, el significado esencial del mismo; su función técnica se concreta tanto en el proceso de formulación de la ley, como ulteriormente en la interpretación y construcción del Derecho penal (Cobo/ Vives).

Estos subprincipios son los siguientes:

3.1. Reserva absoluta de ley para definir injustos penales.- Este subprincipio, que tiene una fundamentación democrático-representativa y cumple una función garantizadora (Tozzini), ha sido denominado por el TC como principio de legalidad o de reserva legal en la sentencia recaída en el Expediente $\mathrm{N}^{\circ} 2050-$ 2002-AA/TC, aunque posteriormente, en la sentencia recaída en el Expediente $\mathrm{N}^{\mathrm{o}}$ 2302-2003-AA/TC lo denominó reserva de ley, mientras que el principio de legalidad, en sentido general, se entiende como la subordinación de todos los poderes públicos a leyes generales y abstractas que disciplinan su forma de ejercicio y cuya observancia se halla sometida a un control de legitimidad por jueces independientes; la reserva de ley, por el contrario, implica la determinación constitucional que impone la regulación solo por ley, de ciertas materias. Es el calificado como tenor literal de la legalidad y entendido como un mero requisito formal. El Tribunal Constitucional alemán (1989), por ejemplo, declaró que su sentido nuclear es el de garantizar la descripción legal de los tipos de delito, es decir, de injusto típico, y no transferir al juez del caso concreto la determinación de lo injusto.

La descripción de la conducta prohibida y de la sanción penal deben estar previstas en una norma con rango de ley de carácter material; es posible que se exprese no solo a través de ley aprobada por el Congreso, sino también por decreto legislativo (Rubio Correa. En contra, A banto Vásquez); no puede haber norma de rango inferior que las establezca (sentencia del Tribunal Constitucional recaída en el Expediente $\mathrm{N}^{\mathrm{o}}$ 0010-2002-AI/TC). La indicada sentencia, a su vez, estimó que cuando existe el mismo tipo delictivo en dos leyes distintas y de vigencia simultánea se vulnera el principio de reserva de ley; lo que concedería un inaceptable grado de discrecionalidad a la autoridad pública.

3.2. Exigencia de determinación, certeza o taxatividad.- Este subprincipio constituye, propiamente, un mandato, esto es, una exigencia clara de determinación 
de las conductas punibles cuyo sustento, además del principio de legalidad, está en el principio de seguridad jurídica -entendido como una garantía a favor del ciudadano frente al sistema penal-. Adriasola postula, siguiendo a Roxin, que propiamente es una garantía contra la arbitrariedad judicial, evitando una excesiva libertad interpretativa y generando en la ciudadanía la seguridad de cuáles son las conductas prohibidas y cuáles, por ende, las permitidas. Al respecto, el TC ha señalado en la sentencia recaída en el Expediente $\mathrm{N}^{\circ} 16-2002-\mathrm{AI} / \mathrm{TC}$, que es un principio que transita todo el ordenamiento incluyendo, desde luego, a la Norma Fundamental que lo preside, y que está reconocido implícitamente en ella a través de distintas disposiciones, entre las que está el artículo $2^{\circ}$.24.a que ratifica la finalidad protectora que persigue el derecho penal.

3.3. La seguridad jurídica, estipuló la sentencia del Tribunal Constitucional recaída en el Expediente $\mathrm{N}^{\mathrm{o}} 1-2003-\mathrm{AI} / \mathrm{TC}$, es un valor superior contenido en el espíritu garantista de la Carta Fundamental que se proyecta hacia todo el ordenamiento jurídico y busca asegurar al individuo una expectativa razonablemente fundada respecto a cuál será la actuación de los poderes públicos y, en general, de toda la colectividad, al desenvolverse dentro de los cauces del derecho y la legalidad. La razón de este mandato reside, a tono con la jurisprudencia constitucional alemana destacada por Jescheck, -así, BverfGE 47, 109 [120]; 48, 48 [56]; y 73, 206 [234]-, por un lado, en que la reserva de ley solo puede desarrollar plenamente su eficacia cuando la voluntad jurídica de la representación popular ha encontrado en el texto una expresión tan clara, que queda excluida la posibilidad de una resolución subjetiva y arbitraria por parte del juez; y por otro lado, en que el mandato de determinación debe asegurar que cualquier persona pueda prever qué comportamiento está prohibido y amenazado con pena.

El TC ha denominado este subprincipio de "tipicidad" en la aludida sentencia, a la vez que en la sentencia recaída en el Expediente $\mathrm{N}^{\circ} 0010-2002-\mathrm{AI} / \mathrm{TC}$ ha precisado que se trata de una prescripción dirigida al legislador para que dote de significado unívoco y preciso al tipo penal, de tal forma que la actividad de subsunción del hecho en la norma sea verificable con relativa certidumbre. El legislador ha de describir qué acción u omisión es seleccionada por la norma penal, qué elementos -objetivos y subjetivos- son singularmente caracterizadores de la cond ucta, y qué sanción penal establece para la ejecución de la misma (Polaino). Por consiguiente, en los tipos penales se debe describir la conducta prohibida con razonable precisión (Adriasola).

Empero, es de aclarar que el principio de legalidad no puede ser entendido de forma tan mecánica que anule la libertad del juez, cuando, en uso de esta, 
ni se crean nuevas figuras delictivas, ni se aplican penas no previstas en el ordenamiento (Bacigalupo). La certeza tiene un carácter relativo, en tanto las palabras y los conceptos no son claros, precisos e inequívocos, de suerte que el texto legal es con mucha frecuencia la exposición incompleta del pensamiento del legislador (Hurtado Pozo).

Compatible con lo expuesto, y desde la perspectiva del Juez penal ordinario, en la interpretación y aplicación de un tipo legal se debe respetar el tenor literal del enunciado normativo $y$, la razonabilidad del resultado interpretativo, de suerte que se respeten tanto las pautas axiológicas que informan la Constitución como los modelos de argumentación comúnmente aceptados y reconocidos por la doctrina (García-Pablos). Previene Tozzini, en esta misma perspectiva, que debe primar el concepto de que el principio de legalidad es una garantía constitucional, y que ella, por lo tanto, debe estar por encima de cualquier método de interpretación, puesto que estos representan únicamente un medio para lograr hacer efectiva la garantía, y no para otorgarle contenido al principio constitucional.

La exigencia de certeza, por lo demás, no colinda con los tipos abiertos que frente a la indeterminación, sobre todo en los conceptos valorativos, delegan al juzgador la labor de completarlos mediante la interpretación; no se exige al legislador una claridad y precisión absoluta en la formulación de los conceptos legales por la naturaleza propia del lenguaje. En la sentencia del Tribunal Constitucional recaída en el Expediente No 1198-2002-AA/TC se admitió la validez de la utilización de los "conceptos jurídicos indeterminados", que definió como "[...] aquellos conceptos o expresiones utilizados por las normas [en] que los límites y términos del enunciado no aparecen perfectamente definidos y que, sin embargo, resultan compartibles con el principio de legalidad mientras puedan concretarse utilizando criterios lógicos, técnicos o de experiencia".

El límite de lo admisible, como insiste Bustos, es que la norma contenga el núcleo fundamental de la materia de la prohibición, de suerte que la interpretación no sea cualitativa, sino meramente cuantitativa (aquí se acoge, por cierto, la denominada "teoría de la esencialidad" expuesta por el TC alemán que exige, como enuncia Bacigalupo, una decisión del legislador sobre todas las cuestiones esenciales que afecten ámbitos normativos básicos y sobre todo en materia de derechos fundamentales). Su concreción -insiste el TC en la sentencia recaída en el Expediente $\mathrm{N}^{\circ} 10-2002-\mathrm{AI} / \mathrm{TC}-$ debe ser razonablemente factible en virtud de criterios lógicos, técnicos y de experiencia, que permitan prever con suficiente seguridad, la naturaleza 
y las características esenciales de las conductas típicas. Sin embargo, otro camino más objetivable sigue el TC alemán, pues sostiene, en relación con los conceptos jurídicos indeterminados, regulados con el recurso a cláusulas generales, que no resulta aceptable otra interpretación que la que aparezca más segura y se corresponda con la convicción general.

Por último, la exigencia derivada del mandato de lex certa no solo se plantea en referencia a la definición de la conducta típica, sino también en lo que respecta a la determinación de la pena con la que esta se sanciona. El legislador debe prever tanto el plazo mínimo de pena y su duración máxima, pues de no ser así resultaría indeterminada, carente de un marco legal. Así lo ha declarado el TC en la sentencia recaída en el Expediente No 10-2002-AI/TC (García Cantizano).

\section{PROHIBICIÓN DE ANALOGÍA (ARTÍCULOS 20.24.D Y 139․9 DE LA CONSTITUCIÓN)}

Incide en la interdicción de creación judicial del derecho, en cuya virtud el Juez no puede desbordar los límites de los términos de la ley y aplicarla a supuestos no previstos en ella (Muñoz Conde/ García Arán). Analogía, precisamente, es un método por el que una regla de ley o de derecho se extiende, por semejanza, a casos no comprendidos en ella, debido a que por la similitud que poseen ambos supuestos de hecho han de ser valorados igualmente (Urquizo Olaechea). El derecho penal impone al juez un límite concreto en su labor interpretativa: debe mantenerse dentro del sentido literal posible del precepto, $\mathrm{y}$, como tal, marca el alcance máximo de toda interpretación, que se hace para evitar el riesgo de inseguridad jurídica que podría suponer un exceso de la orientación objetiva de la interpretación si se centrara exclusiva o desmedidamente en la finalidad de la ley olvidando su tenor (Luzón Peña). El Juez decide, dentro de diversas posibilidades interpretativas, lo que está en la naturaleza de las cosas; no tiene libertad absoluta en la interpretación, está vinculado a las decisiones valorativas legales, que por encargo de la ley se limita a concretar completando la norma en la interpretación (Roxin).

La interdicción de la analogía desfavorable, amén de ser un principio que informa el ejercicio de la jurisdicción, ha sido calificada por el TC en la sentencia recaída en el Expediente $\mathrm{N}^{0}$ 2235-2004-AA/TC como un derecho subjetivo constitucional de los justiciables, concebida, según la sentencia del Tribunal Constitucional recaída en el Expediente $\mathrm{N}^{\circ}$ 274-1999-AA/TC, como una garantía procesal constitucionalmente reconocida, aplicable a los procesos de naturaleza penal, al procedimiento administrativo disciplinario y a todo procedimiento de orden administrativo, público o privado, que se pueda articular contra una persona. 
La norma funciona para prohibir al juez, mediante el recurso de la analogía: a) calificar el hecho como delito o falta; b) definir un estado de peligrosidad; y c) determinar la pena o medida de seguridad que le corresponde (Peña Cabrera).

La sentencia del Tribunal Constitucional, recaída en el Expediente $\mathrm{N}^{\circ}$ 2235-2004-AA/TC no solo ha insistido en precisar que la limitación a los derechos fundamentales -si se impone una pena privativa de libertad, lo es ciertamente-, deberá realizarse en términos necesariamente restrictivos; sino que además indica que se encuentra vedada la interpretación analógica in malam partem de las normas que restrinjan derechos. La sentencia del Tribunal Constitucional recaída en el Expediente $\mathrm{N}^{\mathrm{O}}$ 0010-2002-AI/TC, precisa que la analogía como integración normativa está proscrita en el derecho penal. Debe entenderse como tal aquella que se emplee para fundamentar la represión de un comportamiento mediante la creación de un nuevo tipo legal o la ampliación de uno existente, a partir de la aplicación de la regla a un caso que escapa a su campo de aplicación con arreglo a la similitud de este caso con otro, para lo que es aplicable la regla en cuestión (Hurtado Pozo). No lo está el razonamiento analógico en la interpretación, de suerte que las cláusulas de interpretación analógica tampoco vulneran el principio de lex certa cuando el legislador establece supuestos ejemplificativos que puedan servir de parámetros a los que el intérprete debe referir otros supuestos análogos, pero no expresos.

\section{IRRETROACTIVIDAD DELASNORM ASPEN ALESDESFAVORABLES (ARTÍCULOS 103， SEGUNDO PÁRRAFO, Y 1399.11 DE LA CONSTITUCIÓN)}

Este principio, como variante de la exigencia de lex praevia (sentencia del Tribunal Constitucional recaída en el Expediente $N^{\circ}$ 2496-2005-HC/TC), funciona, esencialmente, para el legislador. En cuanto a la aplicación de normas en el tiempo desde una perspectiva general, el TC ha señalado en la sentencia recaída en el Expediente $\mathrm{N}^{\circ} 1300-2002-\mathrm{HC} / \mathrm{TC}$, primero, que la regla general es su aplicación inmediata: determinados hechos, relaciones o situaciones jurídicas existentes se regulan por la norma vigente durante su verificación; y se gundo, que en el derecho penal material, la aplicación inmediata de las normas determina que a un hecho punible se le aplique la pena vigente al momento de su comisión. En el derecho penal material la acción ha de ser prevista como delito con anterioridad a su realización, la ley solo tiene efectos ex nunc.

Sin embargo, en la sentencia recaída en el Expediente $\mathrm{N}^{\circ}$ 2196-2002-HC/TC aclaró que esa cláusula constitucional se encuentra matizada por el principio 
de favorabilidad, que establece una importante excepción en el caso de que la nueva ley sea más favorable al reo, lo que se explica en el hecho que la prohibición de retroactividad es una prohibición garantista, y establece una preferencia a las leyes que despenalizan una conducta o que reducen la penalidad. La Corte Interamericana de Derechos Humanos, en la sentencia del 31 de agosto de 2004, caso Ricardo Canese vs. Paraguay señaló lo que debe entenderse por ley penal más favorable: "Será [...] tanto aquella que establece una pena menor respecto de los delitos, como la que comprende a las leyes que desincriminan una conducta anteriormente considerada como delito, crean una nueva causa de justificación, de culpabilidad y de impedimento a la operatividad de una penalidad, entre otras". Es decir, comprende todas las categorías del delito: tipicidad, antijuridicidad, culpabilidad y penalidad.

Lo esencial de esta institución es que la nueva ley más favorable no solo beneficia al reo sino que, además, muestra que la valoración jurídica del delito ha cambiado también, por lo que sería injusto castigar con una pena (o con pena más grave) que ya no convence en el momento en que debe imponerse, es decir, tiene su fundamento en el valor justicia, no es un acto de magnanimidad ni se sustenta en la pietatis causa (Cuello Contreras).

El principio de prohibición de retroactividad perjudicial para el reo presenta dos facetas diferentes: a) la garantía criminal, en virtud de la cual ningún hecho puede ser considerado como delito si antes no ha sido expresamente consignado como tal; y b) la garantía penal, que impide infligir pena alguna que no hubiese sido previamente conminada por medio de la ley y en ella descrita exactamente (Polaino Navarrete).

Por otro lado, también ha estipulado que si el juez invoca la vigencia temporal de una norma que no corresponde, vulnera el artículo $103^{\circ}$ constitucional (sentencia del Tribunal Constitucional recaída en el Expediente $\mathrm{N}^{0}$ 32012003-HC/TC). Esta disposición, en la línea sostenida parcialmente por Roxin, solo funciona para leyes penales materiales, no procesales ni penitenciarias (sentencia del Tribunal Constitucional recaída en el Expediente $\mathrm{N}^{\circ}$ 12342000-HC/TC). La no retroactividad es aplicable para las disposiciones que tienen carácter sancionador, como por ejemplo, las que tipifican infracciones, establecen sanciones o presupuestos para su imposición, o las restrictivas o limitativas de derechos; la norma vigente, en ese caso, es la vigente al momento de la comisión del hecho delictivo, no así para las leyes procesales -en el plano jurisdiccional o administrativo penitenciario- en las que el criterio a seguir es la eficacia inmediata de la misma (sentencia del Tribunal Constitucional recaída en el Expediente $\mathrm{N}^{\mathrm{o}}$ 1994-2002-HC/TC). 
La favorabilidad no comprende la aplicación de normas inconstitucionales, aun cuando concedan beneficios al penado (sentencia del Tribunal Constitucional recaída en el Expediente $\mathrm{N}^{\circ}$ 0019-2005-AI/TC, fallo en el que además ha indicado tanto que: "[...] toda ley dictada como parte de la política criminal del Estado será inconstitucional si establece medidas que resulten contrarias a los derechos fundamentales de la personas, procesadas o condenadas. Pero también lo será si no preserva los fines que cumple la pena dentro de un Estado social y democrático de Derecho [...]", como que "[...] la ley declarada inconstitucional, a diferencia de la derogación, 'aniquila' todo efecto que la norma pueda cumplir; incluso los que pueda haber cumplido en el pasado, en caso de que haya versado sobre materia penal o tributaria $[\ldots]$ ").

En el caso del delito continuado, que es solo uno de los supuestos que plantean los tipos de actividad plural o mantenida, el TC en una clara invasión a la jurisdicción ordinaria por tratarse de un tema propio de la dogmática y definición de los alcances de una figura legal, respecto al cual existe un intenso debate doctrinal que se prolonga a toda la institución (Luzón Peña), sostiene que se aplica la última ley, bajo cuya vigencia se cometió el último acto (sentencia del Tribunal Constitucional recaída en el Expediente $\mathrm{N}^{\circ}$ 9012003-HC/TC). La figura del delito continuado y su relación con los supuestos de retroactividad e irretroactividad alcanza características especiales, cuyo eje de solución, dice un sector de la doctrina, estriba en la aplicación de la ley posterior solo si la totalidad de su presupuesto ha sido realizado por el agente durante su vigencia (Vives Antón); mientras, que otro sector doctrinario sostiene que, en función de la finalidad concebida por el artículo $49^{\circ}$ del Código Penal -evitar ciertos casos de reiteración y dar una solución más favorable, de atenuación de la pena- no puede aceptarse la solución de aplicar sin más la nueva ley; en consecuencia, debe aplicarse la ley más favorable entre aquellas vigentes desde el inicio de su ejecución hasta el momento de la sentencia (Hurtado Pozo).

\section{NE BIS IN IDEM O DOBLE PUNICIÓN (ARTÍCULO 1399.13 DE LA CONSTITUCIÓN)}

Es un subprincipio que deriva de la cláusula del Estado de Derecho; empero, el TC en la sentencia recaída en el Expediente $\mathrm{N}^{0}$ 729-2003-HC/TC declaró que tal principio constituye un contenido implícito del derecho al debido proceso reconocido en el inciso 3 del artículo $139^{\circ}$ de la Constitución. La dimensión material de ese derecho fundamental -que según la sentencia recaída en el Expediente $\mathrm{N}^{\circ}$ 2050-2002-AA/TC tiene conexión con los principios de legalidad y proporcionalidad, pues se requiere previsibilidad en la conducta 
sancionadora del Estado- aunque más propiamente en esta última (cfr. García Rivas)-, expresa la imposibilidad de que recaigan dos sanciones sobre el mismo sujeto por una misma infracción. La posibilidad de la imposición de dos sanciones puede tener lugar, y por eso está prohibido con motivo: a) de una investigación o enjuiciamiento de la misma infracción más de una vez en la misma causa; b) de la incoación de dos o más investigaciones o juicios al mismo tiempo por la misma infracción; y c) de una infracción que ya ha sido objeto de decisión final (Pérez Pinzón).

Se requiere identidad de sujeto, hecho y fundamento (el TC peruano ha seguido en este punto lo que estableció el TC español en la sentencia recaída en el Expediente $\mathrm{N}^{\mathrm{o}}$ 2-1981, del 30 de enero). Este último presupuesto es el determinante, pues la identidad del hecho requiere, además, que la punición se fundamente en un mismo contenido de injusto, esto es, en la lesión de un mismo bien jurídico o un mismo interés protegido (sentencia del Tribunal Constitucional recaída en el Expediente $\mathrm{N}^{\mathrm{o}}$ 2050-2002-AA/TC).

Un supuesto propio de la doble incriminación o punición es la prohibición de doble valoración, en cuya virtud de una misma circunstancia o hecho no se pueden extraer dos o más consecuencias con repercusiones en la responsabilidad penal y/o en la punibilidad. Expresión de esta exigencia es el artículo $46^{\circ}$, primer párrafo del Código Penal, en cuanto estatuye que para la determinación judicial de la pena el Juez no debe atender a hechos o circunstancias que no sean específicamente constitutivas del hecho punible o modificatorias de la responsabilidad; es decir, no debe valorar doblemente aquellos elementos componentes de la definición típica o determinadas circunstancias ya consideradas por el legislador en el tipo de injusto. Ello es así porque los tipos penales contienen los requisitos mínimos para que alguien sea castigado de acuerdo con los marcos punitivos previstos en ellos. De ahí que resulta ilógico agravar la pena con la argumentación de que se ha realizado uno de los elementos del tipo. Tampoco puede servir para la agravación de la sanción la circunstancia de que el comportamiento del autor es exactamente el que el legislador quiso prevenir (Jescheck).

Un supuesto particular que puede entrañar la vulneración de la prohibición de doble punición está referido a las personas que pertenecen a pueblos indígenas que tienen su propio sistema de sanciones y de solución de conflictos; por consiguiente, si esa persona ha sido sancionada conforme a la cultura indígena a la que pertenece -la propia Carta Política reconoce la existencia de la jurisdicción indígena y la autoriza a imponer sanciones-, no es posible imponerle una nueva pena $\mathrm{o}$, al menos, debe computar la pena comunitaria como parte de la pena que pretende imponerle (Zaffaroni). 
La reincidencia, incluida en una reciente modificación penal, no afecta el ne bis in idem. Es así porque el primer delito no recibe una pena adicional ni una agravación de esta, y el segundo delito, materia de sanción, no es objeto de una doble imposición de pena, sino de una sola, aunque agravada como consecuencia de los antecedentes previos. La reincidencia tampoco vulnera el principio de culpabilidad, pues se refiere a un hecho del propio imputado, a sus propios antecedentes (sentencia del Tribunal Constitucional recaída en el Expediente $\mathrm{N}^{\mathrm{o}} 0014$ 2006-PI/TC). El problema más patente es la fundamentación de su racionalidad jurídica, el por qué de su naturaleza agravatoria, que el fallo no responde como mereciera, pues a final de cuentas no siendo sólidas las teorías que estiman que la reincidencia supone una mayor culpabilidad o se trata de una causa de agravación del injusto, tal vez la explicación se hallaría en la noción de peligrosidad criminal, entendida como probabilidad de delinquir, ratificada porque el delincuente precisamente volvió a delinquir (Cobo/ Vives).

Es obvio, por lo demás, que en los supuestos de reincidencia la pena se eleva por encima del injusto del hecho, lo que se fundamenta en la persistencia antisocial del autor, aunque indirectamente el TC afirme que la pena agravada no es desproporcionada al no vulnerar el principio del Estado de Derecho, el valor de la justicia, la dignidad de la persona humana y el principio de culpabilidad penal derivado de ella (cfr. sentencia del Tribunal Constitucional español $N^{o}$ 150-91, del 4 de julio). Lo esencial, sin embargo, es que, como advirtió la sentencia del Tribunal Supremo español del 5 de julio de 1991, la reincidencia se fundamenta básicamente por razones de prevención especial -vida del autor anterior al delito-, ajenas a la culpabilidad por el hecho -no representa una causa de aumento de culpabilidad-; en consecuencia, el órgano jurisdiccional penal deberá establecer anticipadamente hasta dónde llega la gravedad de la culpabilidad, pues las necesidades de prevención especial derivadas de la tendencia del autor solo podrán ser contempladas hasta ese límite, que no tiene por qué agotar la máxima pena prevista en abstracto en la ley; tesis que importa una interpretación correctora que es compatible con la sentencia del Tribunal Constitucional alemán del 16 de enero de 1979, la que condicionó la constitucionalidad de la reincidencia siempre que se evitara una presunción de la mayor culpabilidad y se verificara en cada caso si se le podía reprochar al autor reincidente el no haber tomado como advertencia las anteriores condenas (Choclán Montalvo).

\section{PRINCIPIO DE PROPORCIONALIDAD}

Deriva de la cláusula del Estado de Derecho (sentencia del Tribunal Constitucional recaída en el Expediente $\mathrm{N}^{\mathrm{o}} 10-2002-\mathrm{AI} / \mathrm{TC}$ ) y, desde una 
perspectiva general, ofrece elementos para analizar la validez -saber cuáles son los contenidos vinculantes para el legislador que surgen de los derechos a través de un análisis lingüístico de tipo interpretativo y argumentativo-, la aplicación y la fundamentación de las normas constitucionales. La sentencia del Tribunal Constitucional recaída en el Expediente $\mathrm{N}^{\circ}$ 6712-2005-HC/ $\mathrm{TC}$, en esa misma línea apuntó que "[...] a través de la proporcionalidad se procura que cada solución a la cual se arribe responda a una conveniencia constitucional o finalidad de la determinación de contenidos de cada uno de los derechos que están en juego. Es decir, busca que el resultado del acto interpretativo responda al objeto perseguido por la ponderación realizada".

Este principio, que en sede penal afecta al injusto del hecho -no a la atribuibilidad del injusto al autor, propio del principio de culpabilidad-, es decir, a la relación entre la gravedad del injusto y la de la pena (García Pablos), se expresa en una triple dimensión: la intervención restrictiva de los poderes públicos debe ser necesaria, adecuada y proporcionada. Ello significa que la proporcionalidad se mide en abstracto y en concreto; la primera, referida al establecimiento de conminaciones legales, y la segunda, circunscrita a la imposición de penas, y en ambos casos exige, como común denominador, que guarden relación valorativa con el hecho cometido, contemplado este en su significado global (A rroyo Zapatero).

7.1. El subprincipio de necesidad.- Se expresa a través de la exigencia de protección de bienes jurídicos o de dañosidad social, de aquellos valores, bienes o intereses constitucionalmente legítimos en un Estado Constitucional. Así lo ha consagrado el TC en la sentencia recaída en el Expediente $\mathrm{N}^{\mathrm{o}} 19-$ 2005-AI/TC, al decir que "[...] solo la defensa de un valor o un interés constitucionalmente relevante podría justificar la restricción en el ejercicio de un derecho fundamental $[\ldots] "$.

Quintero Olivares previene de una identificación entre derechos fundamentales y bien jurídico. Destaca que la necesidad de que ciertos intereses sean constitucionalmente relevantes -mínimo social ético necesario para la convivencia social, en opinión de la mayoría- no los convierte automáticamente en bienes jurídicos penales. Asimismo, señala que los derechos fundamentales reciben su tutela jurídica en la Constitución y que solamente algunos de ellos -reputados como imprescindibles en el máximo grado- y solo frente a cierto número de ataques, son objeto de protección penal, a partir del cual se transforman en bienes jurídicos para el derecho penal. Además nos dice que el mantenimiento del sistema social, que impone la necesidad de que ciertos intereses sean custodiados penalmente, se sustenta, a veces en derivaciones de 
derechos humanos superiores (v. gr. vida y la integridad física) y otras serán simplemente piezas necesarias para el funcionamiento de la relación social (v. gr. tráfico fiduciario público y privado, la honestidad de los funcionarios públicos, etc.). Esto último no significa, desde luego, una distancia del legislador respecto las exigencias constitucionales, pues ha de requerirse que por lo menos mediatamente, los intereses penalmente protegidos deban vincularse a la Ley Fundamental. En esa misma es de advertir que la Constitución no prevé siempre todos los bienes que son de interés vital para la comunidad, cuyas reglas y principios, por consiguiente, desempeñan el papel de límites negativos en la medida que establecen el ámbito fuera del cual el legislador no debería recurrir al derecho penal (Hurtado Pozo).

Losbienesjurídicosobjetodetutela penal, nosolodebenserconstitucionalmente legítimos -con las matizaciones arriba señaladas-sino que deben ser objeto de jerarquización a fin de dotarlos de una protección penal, de unas penas, proporcionadas en su gravedad. Los jueces, por lo demás, deben exigir que la conducta típica entrañe una lesión o puesta en peligro del bien jurídico tutelado -entraña la expresión del subprincipio de ofensividad o lesividad nullum crimen sine iniuria, que entronca con el contenido material de antijuricidad material-. Desde esta perspectiva, lo que debe incriminarse son hechos y no meros pensamientos, actitudes o modos de vida; afirmación que a su vez incorpora dos subprincipios que se erigen en límites constitucionales objetivofuncionales: nullum crimen sine actione y cogitationis poenam nemo partitur: solo se criminalizan conductas humanas, no meros pensamientos o cualidades de las personas, y se requiere una manifestación exterior de la voluntad criminal, así como que los pensamientos no puedan fundamentar una sanción penal. Es de introducir tres requisitos materiales, cuya discusiónen sedeconstitucional puede ser muy relevante: a) las lesiones de bienes jurídicos tienen que ser, al menos, socialmente intolerables; b) tienen que necesitar el reforzamiento de la producción de costes jurídico-penales derivados de la lesión al bien jurídico, en interés de la común predisposición a la observancia de la norma; y c) tienen que hacer peligrar suficientemente el objeto del bien jurídico. Los dos primeros requisitos conceden al legislador una prerrogativa de valoración y regulación, y el último requiere de una precisión adicional, centrada en la idea de que los actos que se repriman tienen como límite una puesta en peligro de bienes jurídicos cuya máxima permisión se daría ante la presencia de un peligro abstracto cualificado (Bottke).

7.2. El subprincipio de intervención mínima.- El Derecho penal debe ser el último de los recursos, debe ser lo menos gravoso posible para los derechos individuales mientras resulte adecuado para alcanzar los fines de protección 
que se persiguen y debe aplicarse cuando las otras ramas del derecho no resulten suficientes. Cuando el legislador se decide por el derecho penal debe tomar en consideración el nivel de gravedad o peligrosidad de los ataques al bien jurídico; así la gravedad del resultado (si se es delito de resultado o de peligro) y la gravedad de los comportamientos lesivos (dolo o imprudencia).

7.3. El subprincipio deproporcional idad delas penas.- La pena debe ser proporcional al delito y la medida de ella se establece sobre la base de la importancia social del hecho -no pueden ser sancionados los delitos con penas desorbitadas que no guarden una efectiva relación de proporcionalidad entre la gravedad de la acción delictiva y la pena prevista en el tipo legal-. Como tal, este subprincipio está relacionado directamente con el principio de culpabilidad que persigue, como uno de sus elementos fundantes, que la pena no exceda la gravedad equivalente a la culpabilidad. Así, el artículo VIII del Título Preliminar del Código Penal establece la proporcionalidad, en todo caso, como límite máximo, de suerte que el límite hacia abajo es dejado al legislador y al juez para evaluar otros factores informadores de la sanción penal, como por ejemplo la resocialización (García Cavero).

Este subprincipio incide, con mayor rigor, en la dimensión de las penas. Se proyecta, primero, en la fijación legislativa de éstas, y segundo, en su aplicación judicial, con su proyección penitenciaria (sentencia del Tribunal Constitucional recaída en el Expediente $\mathrm{N}^{o} 10-2002-\mathrm{AI} / \mathrm{TC}$ ). Mir Puig ratifica que la proporcionalidad de las penas plantea dos aspectos o exigencias: a) necesidad de que la pena sea proporcionada al delito; y b) exigencia de que la medida de la proporcionalidad se establezca basándose en la importancia social del hecho, en su nocividad social.

La proporcionalidad en este ámbito exige un nivel de adecuación entre gravedad de la pena y relevancia del bien jurídico protegido y, a su vez, entre la pena y las distintas formas de ataque al bien jurídico que la conducta puede presentar (en los que, debe entenderse, no hay un baremo preciso y prefijado).

El juicio de proporcionalidad ha de atenerse a la gravedad del delito y a la finalidad de tutela que corresponde a la pena -criterio último que incluso podía prevalecer sobre el de la gravedad del injusto, si en el caso concreto, las respectivas exigencias de uno $\mathrm{u}$ otro criterio fuesen antagónicas-. Este juicio requiere de una ponderación que asuma valoraciones y comparaciones intrasistemáticas; empero, debe tomarse en cuenta, en este ámbito, que la calificación de desproporcionada de una pena solo podrá tener lugar cuando exista un desequilibro patente y excesivo o irrazonable entre la sanción y 
la finalidad de la norma a partir de pautas axiológicas constitucionalmente indiscutibles, tal como ha sido precisado por el TC español en la Sentencia $\mathrm{N}^{\mathrm{o}}$ 161-1997, del 2 de octubre; anteriormente la sentencia del 4 de julio de 1991, si bien previno que la medida de la pena prevista por la ley para un caso general es competencia del legislador en función de sus objetivos de política criminal, anotó como límite que no exista una desproporción de tal entidad que vulnere el principio del Estado de Derecho, el valor de la justicia, la dignidad de la persona humana y el principio de culpabilidad derivado de ella.

Por otro lado, para la aplicación concreta de la pena es de tomar en cuenta las circunstancias objetivas y subjetivas del delito cometido. La entidad del injusto perpetrado -su gravedad y diversas modalidades- y el grado de culpabilidad -que denota el nivel de exigibilidad achacable al autor del injusto- (Velásquez Velásquez). En consecuencia, es evidente que se debe impedir al juez imponer penas superiores a dicha proporción, pero a su vez se le debe autorizar una respuesta menos intensa en función de la entidad del injusto y de la gravedad por el hecho cometido.

García Cavero plantea, esquemáticamente, los ámbitos de la proporcionalidad abstracta y de la proporcionalidad concreta.

7.3.1. La proporcionalidad abstracta se expresa tanto en el principio de subsidiariedad, analizar los medios con los que cuenta el Estado para alcanzar el fin de la protección, de suerte que no es lícita la intervención punitiva cuando el mismo efecto puede lograrse con medidas menos gravosas, como en que si se admite la necesidad del castigo penal, debe precisarse el tipo de pena y su cantidad que resulten proporcionales al hecho, a su gravedad y a las modalidades de ataque; además la pena debe formularse sobre la base de un límite mínimo y uno máximo, esto es, en función de la lesión mínima del bien jurídico protegido y de la pena más grave permitida por un Estado de Derecho -aquí, entra en consideración el principio de respeto de la dignidad de la persona humana y que la amenaza penal ha de mantenerse dentro de los límites de la racionalidad- (Bustos/ Hormazabal).

7.3.2. La proporcionalidad concreta se observa en la actividad judicial. El juez, dentro del marco dado por la ley penal, debe individualizar la pena. El artículo $46^{\circ}$ del Código Penal reconoce los parámetros de la proporcionalidad, los que se expresan entrela gravedad del hecho delictivo y la gravedad dela pena. El hecho debe apreciarse en todos sus aspectos socialmente relevantes, configurados objetivamente, y la gravedad de la pena, condicionada culturalmente, debe excluir las penas que lesionen el principio de humanidad. 
El TC en la sentencia recaída en el Expediente $\mathrm{N}^{\circ} 0003-2005-\mathrm{AI} / \mathrm{TC}$, realizó el juicio de proporcionalidad de la sanción de la apología terrorista -caracterizado deintensidad media-, analizando sistemáticamente las penas previstas para esa misma figura en relación con los otros supuestos legalmente incorporados: delitos comunes, delitos contra la seguridad pública y otros, y de terrorismo. Refirió, además, la exigencia de una relación entre la importancia de los bienes jurídicos lesionados y la gravedad de la pena prevista, cuya ilegitimación solo se dispondrá si el grado de realización de los bienes jurídicos protegidos por la ley penal resulta notoriamente de menor importancia queel derechoque se verá afectado por la pena que se imponga. También declaró la constitucionalidad de las penas compuestas, sin que ello vulnere el ne bis in idem.

Desde otra perspectiva, pero en la misma línea del citado subprincipio, el TC ha declarado, frente a la derogación del máximo de la pena privativa de libertad temporal que fijaba el originario artículo $29^{\circ}$ del Código Penal, que la regla general de duración máxima de dicha pena temporal es de 35 años de privación de libertad establecidos para la revisión de la cadena perpetua, límite que se justifica en la necesidad de proteger los derechos o bienes constitucionales del condenado y por ser más favorable al imputado (STC $\mathrm{N}^{\circ}$ 965-2004-HC/TC).

\section{PRINCIPIO DE CULPABILIDAD}

Se funda en la dignidad humana, tal como debe entenderse en un Estado democrático respetuoso del individuo, que le exige y le ofrece la posibilidad de evitar la pena comportándose según el derecho; asimismo guarda relación con una cierta seguridad jurídica, pues el ciudadano ha de poder confiar en que dirigiendo su actuación en el sentido de las normas jurídicas no va a ser castigado (Mir Puig). Cabe recordar que el principio de dignidad humana implica el reconocimiento a la autonomía ética de la persona y a su indemnidad personal; la persona es un fin en sí mismo, jamás puede ser medio para otro objetivo, el Estado está a su servicio, y no puede ser considerada como un objeto o quedar sometida a la tutela del Estado (Bustos/ Hormazabal).

El principio de culpabilidad contiene el subprincipio de personalidad de las penas -de imputación personal- y el subprincipio de exigencia de dolo o culpa, que se erigen en elementos que fundamentan la reprochabilidad del autor y traza los presupuestos de la pena. El primero limita la responsabilidad a los autores del hecho delictivo y a los que participan en él como instigadores y cómplices. El segundo rechaza la responsabilidad objetiva -por el mero resultado-, el delito debe cometerse con dolo o culpa -de propósito o por una inexcusable falta de cuidado-. 
Cabe indicar, desde ya, que el principio de culpabilidad no es determinante en forma absoluta del concepto de culpabilidad de la teoría del delito; naturalmente influye en él, pero sin determinar su estructura (Bacigalupo). A los fines de garantía que exige la política criminal se distingue el principio de culpabilidad y las garantías democráticas que entraña el concepto de culpabilidad, su fundamento y funciones, este último objeto de una profunda discusión en la dogmática penal. La unanimidad, sin embargo, es relevante cuando se concibe la culpabilidad como principio, a partir del cual se extraen una serie de consecuencias limitadoras, que son las esbozadas en el párrafo anterior: exigencia de dolo o culpa, la pena debe contraerse al hecho propio y la necesidad de que se tenga en consideración la situación concreta en la que el autor se encontraba al tiempo de cometer el delito (Quintero Olivares).

La responsabilidad, parte de la premisa, destacada por el artículo VII del Título Preliminar del Código Penal, que solo se puede aplicar una sanción cuando la voluntad humana se manifiesta en el mundo exterior convirtiéndose en una conducta objetiva -están proscritas, por consiguiente, el puro pensamiento, las meras ideas o los simples motivos, siempre que no se traduzcan en la ejecución externa de una acción desvalorada por el ordenamiento jurídico-. La expresión más notoria de ese principio - del hecho propio- es la exigencia de realización de conductas externas que modifiquen los procesos vitales de otras personas o las relaciones sociales del mundo organizado, exigencia que se extiende a las omisiones típicas que si bien no pertenecen al mundo de la naturaleza ni tienen fundamento ontológico forman parte de las modalidades de conducta relevantes penalmente (Castillo Alva).

El sujeto siempre ha de ser motivable psicológicamente por las normas, es decir, debe reunir las condiciones psíquicas de madurez social para poder captar el sentido de las prohibiciones penales: este es el subprincipio de atribuibilidad o de normal motivabilidad; el delito debe pertenecer al autor como obra de un ser responsable, de una racionalidad normal. Entonces normativamente la reprochabilidad o atribuibilidad solo es posible cuando se reúnen tres requisitos: a) normalidad mental de la persona; b) presencia o posibilidad de presencia de una concreta relación psíquica del sujeto con el hecho; y c) normalidad de las circunstancias en las que actúa (Pérez Pinzón).

El otro subprincipio es el de responsabilidad subjetiva, en cuya virtud el castigo del agente requiere que hay a sido requerido (dolo) o se hay a debido, al menos, a imprudencia; el castigo solo se impone por las consecuencias queridas o previsibles de los propios actos de las personas (García Pablos).

El TC, sobre el particular, estipuló que se está ante un límite a la potestad 
sancionadora del Estado, y que no es constitucionalmente aceptable que una persona sea sancionada por un acto o una omisión de un deber jurídico que no le sea imputable (sentencia del Tribunal Constitucional recaída en el Expediente $\mathrm{N}^{\mathrm{o}}$ 2868-2004-AA/TC). Este principio deriva del principio de dignidad humana y de la idea de Estado de Derecho, e indirectamente, desde lo procesal, de la presunción de inocencia.

El TC en la sentencia recaída en el Expediente $\mathrm{N}^{\circ}$ 0010-2002-AI/TC insistió en que el principio de culpabilidad es una exigencia de la cláusula del Estado de Derecho y constituye un principio constitucional implícito que limita la potestad punitiva del Estado y, además, es una garantía para los ciudadanos. Las normas constitucionales implícitas, por cierto, son aquellas que pueden encontrarse dentro de la razón de ser o de la finalidad de las normas existentes en el derecho positivo, pero que no han sido escritas literalmente dentro de ellas (Rubio Correa).

\section{PRINCIPIO DE RESOCIALIZACIÓN}

Dos preceptos son pertinentes. Se trata de los numerales 22 y 21 del artículo $139^{\circ}$ de la Constitución que indican, primero, que el régimen penitenciario tiene por objeto la reeducación, rehabilitación y reincorporación del penado a la sociedad; y segundo, que los reclusos y los sentenciados tienen derecho a ocupar establecimientos adecuados. Esos preceptos no reducen los fines de la pena a la prevención especial, ni conciben al tratamiento como contenido de la ejecución penitenciaria -los términos utilizados se refieren al contenido de la ejecución, no a su sentido de resultado final-. Se entiende, con cierto consenso doctrinario, que el Estado debe construir un sistema de ejecución de la pena que ofrezca -no le imponga- al condenado medios y oportunidades para su reinserción, así como contar con sistemas jurídicos que puedan facilitar la resocialización sin lesionar los objetivos de prevención general, y eliminar factores que incrementan la asociabilidad del interno -una de cuyas más claras expresiones es la superpoblación penitenciaria, que Villavicencio denomina el fenómeno de la prisonización-, sin perjuicio, luego, de introducir programas de asistencia postpenitenciaria.

El TC, por su parte, ha descartado que la retribución absoluta se conciba como el fin de la pena, sin dejar de desconocer el que toda pena trae consigo un elemento retributivo, pues asumir tal concepción unívoca niega al reo su condición de persona humana (sentencia recaída en el Expediente $\mathrm{N}^{\circ}$ 0019-2005-PI/ TC). Por otro lado, ha sostenido que la Ley Fundamental ha constitucionalizado la teoría de la prevención especial positiva, al incorporar un principio cons- 
titucional penitenciario de la readaptación social de los penados, que obliga al legislador a regular las condiciones de su ejecución y, antes, a establecer el quantum de las penas (sentencia recaída en el Expediente $\mathrm{N}^{\circ} 0010-2002-\mathrm{AI} /$ TC). Reconoce, a su vez, que la pena privativa de libertad es el primer efecto reeducador en el delincuente, quien internaliza la seriedad de su conducta delictiva e inicia su proceso de desmotivación hacia la reincidencia, a lo que denomina prevención especial de efecto inmediato (sentencia recaída en el Expediente $\mathrm{N}^{\mathrm{o}}$ 0019-2005-PI/TC). Pero también, admite el valor de la prevención general, que incide en el colectivo y tiene por finalidad influir en la sociedad a través de la efectividad de la amenaza penal y su posterior ejecución en aquellos que, mediante una conducta antijurídica, atentan contra valores e intereses de significativa importancia y, por tal motivo, son objeto de protección por el derecho penal (sentencia recaída en el Expediente $\mathrm{N}^{0}$ 0019-2005-PI/TC). El TC en la sentencia recaída en el Expediente $\mathrm{N}^{\mathrm{o}}$ 0014-2006-PI/TC sostiene, como corolario, que las teorías preventivas, tanto la especial como la general, gozan de protección constitucional directa; es decir, opta, a semejanza de la Corte Constitucional italiana, por el principio de la multifuncionalidad de la pena, de suerte que la finalidad reeducadora es compatible con todas las otras posibles finalidades de la pena (Palazzo), claro está, en la medida en que se privilegie la retribución con seria lesión y desnaturalización de prevención, especial y general.

Esta apuesta de la pena como instrumento de prevención del delito, sin desconocer, por lo menos indirectamente, la función que asume como retribución de la culpabilidad, en orden a determinar las vías constitucionalmente aceptables para asegurar la vigencia de las normas sociales, permite reconocer una clasificación basada en quién sea el sujeto en el que se pretende que la pena influya en términos de prevención: la prevención especial o individual, que incide en el propio autor, y la prevención general, que incide en la generalidad de las personas (Stratenwerth).

Por otro lado, en la sentencia recaída en el Expediente $\mathrm{N}^{\mathrm{o}}$ 0014-2006-PI/TC, respecto a la habitualidad, el Tribunal Constitucional ha sancionado que no infringe principios tales como el de proporcionalidad, lesividad y trato igualitario. Precisa dos ideas: a) que esa calificación jurídico-penal, que importa una más intensa reacción penal, no ingresa al ámbito de la personalidad del autor castigando con una mayor pena su modo de vida; $y$, b) que la resocialización no es el único fin de la pena, pues también es una obligación del Estado proteger otros bienes constitucionales, entre ellos, la seguridad de los ciudadanos (vide artículo $44^{\circ}$ de la Constitución). 
Empero, es de rigor tomar en cuenta que los dos argumentos en cuestión no responden al núcleo de esa institución y a sus cuestionamientos dogmáticos.

\section{PRINCIPIO DE RESPETO Y PROTECCIÓN A LA DIVERSIDAD CULTURAL}

Es un criterio especializado y particularmente notable desde la perspectiva nacional del principio de igualdad, vinculado a la exigencia del respeto a la identidad cultural de las comunidades campesinas y nativas (vide artículos $2^{\circ} .19$ y $89^{\circ}$ de la Constitución), cuyos miembros tienen derecho a tener su propia vida y cultura, con todas sus manifestaciones (sentencia del Tribunal Constitucional recaída en el Expediente $\mathrm{N}^{\circ}$ 0872-1999-AA/TC). Se debe respetar los derechos de los individuos integrantes de los diferentes grupos étnicos, propiamente, los integrantes de pueblos y culturas originarias y ancestrales del Perú, sentencia del Tribunal Constitucional recaída en el Expediente $\mathrm{N}^{\mathrm{o}} 0042-2004-\mathrm{AI} / \mathrm{TC}$ con relación a sus tradiciones, costumbres, etc. Con ello, postula el TC en la sentencia recaída en el Expediente $\mathrm{N}^{\mathrm{o}} 0020$ 2005-AI/TC, se reconoce el multiculturalismo y plurietnicidad de la nación peruana, que a su vez concreta el Estado social y democrático de derecho establecido en el artículo $43^{\circ}$ de la Constitución. El respeto al patrimonio cultural inmaterial que infunde a sus miembros un sentimiento de identidad y continuidad, afirma el TC en la sentencia recaída en el Expediente $\mathrm{N}^{\circ} 0042-$ 2004-AI/TC, contribuye a promover el respeto de la diversidad cultural y la creatividad humana.

Este principio en el que residen valores constitucionales como el pluralismo, la tolerancia y el respeto por la costumbre, idiosincrasia y cosmovisión ajena (sentencia del Tribunal Constitucional recaída en el Expediente $\mathrm{N}^{\circ}$ 0020-2005-AI/TC), cumple en sede penal, una doble función: el derecho a ser juzgados en atención a su cultura y costumbres, y si el delito se comete en el ámbito geográfico de su comunidad y en relación con sus patrones culturales, a ser pasibles del modelo de solución de conflictos propios de su cultura (Villavicencio), artículo $149^{\circ}$ de la Constitución; lo cual representa el reconocimiento no solo de un cierto pluralismo jurídico, en el que los derechos de las comunidades campesinas y nativas constituyen una especie de subsistemas jurídicos, sino también de una justicia de carácter tradicional que admite y respeta (Cárdenas Krenz). En este último punto, el TC en la sentencia recaída en el Expediente $\mathrm{N}^{\mathrm{o}}$ 6167-2005-HC/TC aclaró que el reconocimiento de fueros especiales no vulnera el principio de igualdad ante la ley, en tanto asegure todas las garantías vinculadas al debido proceso y 
a la tutela judicial efectiva (aunque, claro está, debidamente adaptadas a la estructura y funcionamiento histórico de la jurisdicción especial indígena).

\section{1. ¿INTERPRETACIÓN CONSTITUCIONAL DE LA LEGISLACIÓN PENAL ORDINARIA?}

Las decisiones del Tribunal Constitucional también han recaído en concretas interpretaciones de las normas penales ordinarias -de dudosa competencia del orden jurisdiccional constitucional-, a cuyo efecto se ha valido, en sede de jurisdicción, de la libertad de diversas instituciones del derecho penal. Algunas de ellas serán así:

11.1. El TC ha establecido que la prescripción de la pena, conforme a los artículos $80^{\circ}$ y $86^{\circ}$ del Código Penal, prescribe a los quince años (sentencia del Tribunal Constitucional recaída en el Expediente $\mathrm{N}^{0}$ 590-2002-HC/TC). Desde luego, la invocación al artículo $80^{\circ}$ del Código Penal es impertinente por regular otra modalidad de prescripción -del delito, no de la pena- y estar sujeta a una regulación propia.

11.2. El delito de desaparición forzada es de naturaleza permanente mientras no se establezca el destino o paradero de la víctima (sentencias del Tribunal Constitucional recaídas en los Expedientes $\mathrm{N}^{\mathrm{o}} \mathrm{s}$ 2488-2002-HC/ TC y 2529-2003HC/TC). La sentencia del Tribunal Constitucional recaída en el Expediente $\mathrm{N}^{\mathrm{o}}$ 2798-2004-TC/HC señaló, por su parte, que ese delito es pluriofensivo porque afecta la libertad física, el debido proceso, la integridad personal, el reconocimiento de la personalidad jurídica y la tutela jurisdiccional; además de ser un delito de lesa humanidad de extrema gravedad.

11.3. La circunstancia agravante de pluralidad de personas en la comisión del delito de TID -artículo $297^{\circ} .6$ del Código Penal- no exige la condena de tres o más personas, pues solo se requiere probar la intervención en el hecho de ese número de personas (sentencia del Tribunal Constitucional recaída en el Expediente $\mathrm{N}^{\mathrm{o}}$ 2212-2004-HC/TC).

11.4. La asociación ilícita es un delito en sí mismo y requiere, para su configuración, en el agente una vocación de permanencia que no se presenta en la simple coparticipación delictiva (sentencia del Tribunal Constitucional recaída en el Expediente $\mathrm{N}^{\mathrm{o}}$ 4118-2004-HC/TC).

11.5. El delito de peculado permite incorporar al administrador de hecho, en tanto por su poder y adscripción al órgano administrativo le permita tener 
la custodia y administración de caudales públicos (sentencia del Tribunal Constitucional recaída en el Expediente $\mathrm{N}^{\circ}$ 2758-2004-HC/TC).

11.6. El delito de peculado requiere, entre otros elementos, de la calificación de los fondos utilizados como públicos, no pudiendo configurarse el tipo penal si se tratase de dinero de fuente privada (sentencia del Tribunal Constitucional recaída en el Expediente $\mathrm{N}^{\circ}$ 0139-2002-HC/TC).

11.7. El delito de asociación ilícita requiere que el agente forme parte de una organización de dos o más personas destinada a cometer delitos, por lo que el tomar parte de un delito aislado no puede dar lugar a la sanción por dicho delito. Este delito requiere una vocación de permanencia que no se presenta en la participación delictiva, la cual opera ante la comisión de un delito aislado (sentencia del Tribunal Constitucional recaída en el Expediente $\mathrm{N}^{\circ} 4118-2004$ $\mathrm{HC} / \mathrm{TC})$.

11.8. La duplicación del plazo de prescripción solo alcanza a los funcionarios públicos por atentar contra el patrimonio del Estado o de organismos sostenidos por este (sentencias del Tribunal Constitucional recaídas en los Expedientes $\mathrm{N}^{\mathrm{o}} \mathrm{s} 1805-2005-\mathrm{HC} / \mathrm{TC}$ y $\left.6136-2005-\mathrm{HC} / \mathrm{TC}\right)$. La primera sentencia señala que esa misma norma establece que existe una dimensión subjetiva del derecho de la legalidad penal, que incluye supuestos tales como la creación de delitos o faltas y sus correspondientes supuestos de agravación o, incluso, la aplicación de determinados tipos penales a supuestos no contemplados en ellos (párrafo 29). Hace, además, una definición de la autoría y participación y de lo que significa un aparato de poder organizado, aunque sin mayores aportes (párrafos 35 y 36).

Por lo demás, en la sentencia del Tribunal Constitucional recaída en el Expediente $\mathrm{N}^{\mathrm{o}} 4118-2004-\mathrm{HC} / \mathrm{TC}$, siguiendo el modelo español (cfr. sentencias del Tribunal Constitucional español $N^{\circ} 137$ y 151-1997) de dudosa equiparidad en sede nacional por los límites que contiene el artículo $200^{\circ} .2$ in fine de la Constitución, en ese ángulo afirmó que la intervención de la justicia constitucional, por vulneración del principio de legalidad, procedería cuando el juez penal se aparta del tenor literal del precepto o cuando la aplicación de un determinado precepto obedezca a pautas interpretativas manifiestamente extravagantes o irrazonables, incompatibles con el ordenamiento y su sistema material de valores. Más allá del recurso a la literalidad de la norma y a la idea de lo irrazonable de su interpretación, cabe reconocer desde el principio de proporcionalidad que los límites de ese enjuiciamiento en sede constitucional se halla constituido por el amplio margen de libertad que ha de reconocerse al legislación ( $\mathrm{y}$, consecuentemente al Juez) en esta materia (Cobo/ Vives). 